\title{
DISCURSO, CULTO AO CORPO E IDENTIDADE: REPRESENTAÇÕES DO CORPO FEMININO EM REVISTAS BRASILEIRAS
}

\author{
Débora de Carvalho Figueiredo ${ }^{* *}$ \\ Universidade Federal de Santa Catarina \\ Departamento de Língua e Literatura Estrangeiras \\ Florianópolis, SC, Brasil \\ Fábio Santiago Nascimento ${ }^{* * *}$ \\ Universidade Federal de Santa Catarina \\ Colégio de Aplicação \\ Florianópolis, SC, Brasil \\ Maria Eduarda Rodrigues ${ }^{* * *}$ \\ Universidade Federal de Santa Catarina \\ Departamento de Língua e Literatura Estrangeiras \\ Florianópolis, SC, Brasil
}

\begin{abstract}
Resumo: Neste artigo, investigamos as representações do corpo feminino em revistas femininas brasileiras, de modo a interpretar e explicar como os novos modelos de corporeidade e identidade estão ligados ao fenômeno da comodificação do discurso e, principalmente, à cultura de consumo. Cinco capas de revistas foram analisadas sob uma perspectiva sistêmico-funcional da linguagem (HALLIDAY, 2004). Nossa análise demonstra que o foco visual nos atributos fisicos das modelos, em combinação com as chamadas de capa nomeando esses atributos e/ou avaliando os produtos anunciados, constroem o vínculo entre o discurso do culto ao corpo e o discurso da comodificação. A aquisição de produtos e serviços, desse modo, torna-se uma prerrogativa inescapável na vida de mulheres brasileiras que buscam individualmente a promessa de saúde, beleza e sucesso, de acordo com suas capacidades de compra.
\end{abstract}

Palavras-chave: Análise crítica do discurso. Revista feminina. Culto ao corpo. Comodificação. Modernidade tardia.

\footnotetext{
* Este artigo foi produzido como parte do projeto "A representação de identidades corporais no discurso midiático: o papel do culto ao corpo na construção de identidades femininas na modernidade tardia", coordenado pela primeira autora.

${ }^{* *}$ Dra. em Inglês/Linguística Aplicada. E-mail: deborafigueiredo@terra.com.br

*** Dr. em Inglês/Linguística Aplicada. E-mail: fabiosantiagonasc@gmail.com

**** Doutoranda do Programa de Pós-graduação em Inglês - Estudos Literários, UFSC. mari.eduardarodrigues@gmail.com 
Com as mudanças tecnológicas e sociais dos tempos pós-modernos, o sentido de identidade individual e social se fragmenta diariamente. Mulheres são particularmente afetadas, uma vez que, como objetos centrais de desejo e de consumo num mercado heteronormativo, sofrem pressões constantes de inúmeros discursos persuasivos para adequarem-se ao padrão hegemônico de beleza feminino. Seus corpos se tornam lócus de comodificação nos discursos que promovem os tratamentos corporais, as práticas de emagrecimento, as academias de ginástica e a cirurgia plástica, para citar apenas algumas das muitas práticas de embelezamento e disciplinas corporais. Na cultura de consumo, a mulher é estimulada a parecer eternamente jovem, magra e bonita. Ao disciplinar e manipular seu corpo, a mulher contemporânea se transforma e, dessa forma, medeia a relação entre a uma identidade própria e uma identidade social imposta pela sociedade de consumo. A manutenção desse (im)possível corpo perfeito é construída através de muito autocontrole e sofrimento.

Neste artigo, investigamos como cinco revistas femininas brasileiras voltadas para a temática do culto ao corpo (Boa Forma, Corpo a Corpo, Dieta Já!, Shape e Women's Health) representam as transformações corporais verificadas nesse momento da pósmodernidade, os novos modelos de corpos e os novos estilos de vida, especialmente sob o impacto de técnicas disciplinares como o vestuário, as dietas alimentares, os exercícios físicos e as cirurgias plásticas cosméticas. Nosso objetivo é interpretar e explicar como os novos modelos de corporeidade apresentados na mídia do terceiro milênio, as técnicas disciplinares utilizadas para construir esses modelos corporais, e consequentemente as novas possibilidades de construção identitária abertas para os indivíduos, estão ligados ao discurso promocional, ao fenômeno da comodificação do discurso e, principalmente, à cultura de consumo.

\section{IDENTIDADE E COMODIFICAÇÃO NA PÓS-MODERNIDADE}

Na pós-modernidade, a vida humana se processa em meio à globalização, a comunicação instantânea, a volatilidade do capital, a ação à distância e a predominância da mídia na constituição do universo simbólico das grandes massas. Com relação à construção da subjetividade ${ }^{1}$, ela vem sendo cada vez mais caracterizada como uma propriedade emergente das relações sociais (JACKSON, 1999). Por exemplo, Giddens (1991) vê a identidade como um projeto reflexivo, moldado pelas instituições da pósmodernidade e mantido através de narrativas do eu que são permanentemente monitoradas e revisadas ${ }^{2}$. No processo de articulação dessas narrativas, o consumo

\footnotetext{
${ }^{1}$ No escopo deste artigo, entendemos as identidades como efeitos do discurso, em contraste com a subjetividade, vista como construção do "eu".

2 Como exemplo do monitoramento e revisão das identidades no marco da pós-modernidade e do capitalismo globalizado neoliberal, podemos citar as mudanças na ética do trabalho e do prazer, ocorridas marcadamente a partir da segunda metade do século XX. Enquanto até a primeira metade do século o trabalho era visto como aquilo que dignificava o indivíduo, sendo o lazer e o prazer adiados para depois do trabalho e concebidos como recompensas pelo trabalho bem feito, pelo cumprimento do 'dever', na contemporaneidade os discursos do consumo nos bombardeiam todos os dias com a noção de que o prazer pode e deve ser constante, a felicidade permanente e de alcance rápido e imediato, levando inclusive à 
desempenha um papel central. O 'gosto' do consumidor, segundo Bourdieu (1984), pode ser visto como uma das formas cruciais do capital cultural dos atores sociais, delineado ao longo de linhas de classe social. E a 'forma de sociedade' escolhida (ou dominante) determina também nossas escolhas relativas aos cuidados, à forma e à apresentação de nossas identidades corporificadas. Como aponta Bauman (2001, p. 64), não temos realmente a opção de escolher ficar de fora do projeto contemporâneo do indivíduo: "a individualização é um destino, não uma escolha: na terra da liberdade individual de escolha, a opção de escapar à individualização e de se negar a participar no jogo individualizante não faz parte, de maneira alguma, da agenda".

Na contemporaneidade, uma nova lógica cultural "coloniza" as mentes, os hábitos, as fantasias e os desejos. O imaginário, as pulsões da intimidade, as maneiras de ser e os sentimentos foram incorporados ao universo das mercadorias através de narrativas estéticas e da cultura (FRIDMAN, 1999). Entretanto, o acesso aos recursos requeridos para a autoafirmação dos indivíduos é marcadamente desigual, determinado por divisões de classe, de raça e de gênero. Na luta pela individualização, os extratos sociais se diferenciam pelo leque de identidades ao seu alcance e pela facilidade/dificuldade de 'escolha' entre elas.

Por essa lógica comodificada e compulsória, “a 'individualização' consiste em transformar a 'identidade' humana de uma coisa 'dada' em uma 'tarefa'" (BAUMAN, 2001, p. 183), tarefa essa que passa a ser de inteira responsabilidade dos atores sociais, que têm também que arcar com as consequências de seu desempenho ao tentar forjar para si identidades vitoriosas e bem-sucedidas. Essa tarefa não pode estar mais clara do que em nosso empenho em forjar uma identidade corporal concebida como projeto individual, estilo pessoal, singularidade.

Uma vida longa e adequada, que nos permita consumir todos os prazeres que o mercado oferece, é hoje o valor máximo e o principal objetivo dos esforços da vida. Isso inclui, é claro, nossos corpos, que, como instrumentos de experiências e de gozo, devem ser alimentados com os prazeres à venda. Ao mesmo tempo, o corpo é nossa posse mais preciosa, aquela que deve ser constantemente resguardada e defendida contra um mundo que conspira para enfraquecê-la e destruí-la (BAUMAN, 2001). A contradição entre essas duas exigências (comodificar e utilizar o corpo como fonte e objeto de prazer por um lado, e por outro lado mantê-lo protegido e resguardado) gera ansiedade constante, contribuindo para muitas das típicas mazelas do eu contemporâneo: da insatisfação generalizada com nossa aparência e forma corporal, às depressões, distúrbios alimentares, fobias, crises de pânico, comportamentos aditivos.

Nosso estado contemporâneo de constante incerteza e perplexidade identitários não provêm somente da dificuldade em obter as identidades de nossa 'escolha' e vê-las reconhecidas por nossos pares, mas, sobretudo, da dificuldade de saber que identidade escolher e como nos mantermos sempre alertas e abertos para escolher novas identidades, caso o modelo selecionado tenha saído de mercado ou perdido seu status e poder de sedução (BAUMAN, 2001).

ressignificação do trabalho como forma de prazer (os lemas neoliberais são 'faça apenas o que você gosta', 'ame a si mesmo', 'você merece', 'seja feliz agora, e não depois'). Nessa linha, narrativas do eu que sejam lentas, que impliquem fechamento e prazer tardios ou adiados, são malvistas, passando a significar 'falhas' da subjetividade, por exemplo, falta de empreendedorismo, falta de empenho, falta de ambição. 
Nas sociedades contemporâneas individualizadas e mercantilizadas em que vivemos, a corporeidade passou a ocupar um papel central, ou seja, nos preocupamos cada vez mais com a performance, as aparências, a estetização da vida. Uma das evidências dessa tendência é a forte e constante preocupação dos indivíduos com a apresentação e a forma de seus corpos, na tentativa de adequá-los a um ideal hegemônico de beleza jovem, magra e exercitada. Podemos chamar esse fenômeno moderno de culto ao corpo, entendido como o:

\footnotetext{
Tipo de relação dos indivíduos com seus corpos que tem como preocupação básica o seu modelamento, a fim de aproximá-lo o máximo possível do padrão de beleza estabelecido. De modo geral, o culto ao corpo envolve não só a prática de atividade física, mas também as dietas, as cirurgias plásticas, o uso de produtos cosméticos, enfim, tudo que responda à preocupação de se ter um corpo bonito e/ou saudável. (CASTRO, 2003, p. 15).
}

O culto ao corpo, intimamente ligado à construção do moderno, é um fenômeno criado, sustentado e reforçado por uma gama de discursos públicos e privados, e por uma rede de práticas discursivas e sociais. Para compreender o fenômeno da corporeidade e do culto ao corpo, precisamos investigar sua ligação com a formação reflexiva das identidades na pós-modernidade. A reflexividade, traço fundamental das sociedades contemporâneas, é aqui entendida como o "uso sistemático de conhecimento sobre a vida social para organizá-la e transformá-la" (FAIRCLOUGH, 2001). E esses conhecimentos são utilizados também para nos construirmos como indivíduos. Os conceitos de identidade e de 'eu' tendem a estar associados a um foco interacional no processo de construção de identidades individuais ou coletivas através do discurso. Como pano de fundo para esses conceitos, temos as teorias sociais que explicam a pós-modernidade como um período de identidades múltiplas, mutáveis e fragmentadas. Nessa perspectiva, a criação de identidades é um dos temas mais correntes nas sociedades contemporâneas, e um dos principais focos do fenômeno contemporâneo da reflexividade.

Na pós-modernidade, estamos todos engajados na "política da vida", definida por Giddens (1991, p. 155-156) como "engajamentos radicais que procuram incrementar as possibilidades de uma vida realizada e satisfatória para todos e para qual não existem 'outros' (envolvendo decisivamente uma "ética do pessoal" e a política referida a estilos de vida)". Tornamo-nos seres reflexivos, examinando cada um de nossos movimentos, e raramente nos sentindo satisfeitos com o que vemos. Entretanto, como lembram Chouliaraki e Fairclough (1999), essa reflexividade não nos torna necessariamente capazes de conectar nossos movimentos e 'escolhas' aos seus resultados e consequências. Dizer que vivemos num período de alta reflexividade individual não é o mesmo que dizer que todos os sujeitos sociais possuem um alto grau de consciência crítica, nem que todos se dão conta das implicações ideológicas de suas práticas discursivas. Diferentes posições sociais dentro de hierarquias de classe, raça e gênero, dentre outras, vão implicar diferentes formas de usar o discurso e as linguagens em distintas práticas sociais.

Giddens (1991) argumenta que se tornar um agente social competente - isto é, ser capaz de participar em pé de igualdade com os demais na produção e reprodução de 
relações sociais - requer um monitoramento constante, e bem-sucedido, do rosto e do corpo. Essa competência social implica não apenas ser capaz de controlar o corpo de forma constante e cuidadosa em todas as interações sociais, mas ser visto pelos demais como alguém capaz de exercer esse controle. O controle rotinizado do corpo permite que os indivíduos criem para si um casulo protetor nas interações sociais diárias (GIDDENS, 1991, p.56).

O controle do corpo ocupa um papel importante na comunicação não verbal. $O$ corpo pode ser visto como lócus comunicacional por duas vias: através do gestual e da linguagem, e através da forma, "que é culturalmente codificada para operar como um indicador de poder social e de prestígio" (CASTRO, 2003, p. 15). As principais formas de distinguir-se socialmente via corpo são o consumo alimentar (e.g. dietas) e o cultural, e a forma de apresentação do corpo (incluindo vestuário, cosméticos, higiene, cuidados e manipulação do corpo). A consciência do corpo, necessária para que o indivíduo perceba a complexidade do momento, inclui estar ciente do imperativo dos exercícios físicos e das dietas. Assim, o culto ao corpo tornou-se um imperativo na cultura ocidental contemporânea, e não segui-lo gera sentimentos de culpa e inadequação.

Dentro deste quadro, o corpo torna-se o aspecto visível do eu, e passa a estar, também, sob a égide do fenômeno contemporâneo da reflexividade. A construção reflexiva da autoidentidade e de uma narrativa biográfica coerente é auxiliada pelo acesso a sistemas peritos constituídos por especialistas (tais como médicos, terapeutas, advogados, cientistas e técnicos) com conhecimento técnico altamente especializado, do qual somos todos cada vez mais dependentes (FAIRCLOUGH, 2001). A transferência de conhecimentos dos peritos para os leigos pode se dar através da interação face a face (e.g. terapia, consulta médica), ou de formas mediadas de interação (e.g. cartas, e-mails, telefonemas) ou quase-interação (e.g. livros, revistas, manuais). Os sistemas peritos incluem não só a ciência e os trabalhos acadêmicos, mas todos os tipos de manuais, guias, trabalhos terapêuticos, livros de autoajuda e a mídia de massa, que contribuem para a reflexividade moderna. Esses sistemas e seus discursos não apenas discutem ou representam os processos sociais, na verdade eles são materiais que constituem, ao menos em parte, esses processos (GIDDENS, 1991, p. 2).

\section{CULTO AO CORPO E CONSUMO NO DISCURSO DA MÍDIA}

Como já apontado, na modernidade tardia, a consciência social tornou-se externalizada, isto é, as pessoas recorrem a sistemas peritos e a especialistas que as ajudam a organizar a informação, o know-how, as formas de raciocínio, etc., necessárias para que possam lidar com os aspectos mais íntimos e pessoais do seu ser (SMITH, 1990, apud CHOULIARAKI; FAIRCLOUGH, 1999). No pensamento social de Giddens, a reflexividade moderna está ligada com o recurso aos sistemas peritos, principalmente aqueles materializados através da escrita. Segundo ele, "as experiências mediadas, a partir da primeira experiência da escrita, há muito têm influenciado tanto a auto-identidade quanto a organização básica das relações sociais" (1991, p. 4). Ou seja, a manutenção da confiança nos especialistas e nos sistemas tornou-se condição essencial para a sensação de continuidade da vida. 
Em termos de culto ao corpo, a imprensa vem se caracterizando como um espaço privilegiado de informações relativas ao corpo. Nas revistas femininas, por exemplo, vemos a figura do especialista que dá dicas de beleza, moda, dieta, exercícios físicos, sexualidade, etc. As revistas femininas funcionam como manuais de orientação para a vida diária (HEBERLE, 2004). Elas medeiam mídia e sociedade, ou seja, o conteúdo dessas revistas serve como ponte entre as tendências, os valores e os padrões sociais relativos ao corpo, e as necessidades mercadológicas dos produtos a serem vendidos, ou seja, entre a "lógica dos usos e a lógica da indústria cultural" (CASTRO, 2003, p. 16).

Segundo Castro, "a mídia e a indústria da beleza são aspectos estruturantes do culto ao corpo" (2003, p. 109). No caso da mídia, ela medeia a temática e a mantém sempre presente na vida cotidiana, informando a leitora/espectadora sobre as últimas novidades e descobertas tecnológicas e científicas, ditando e incorporando tendências. A indústria da beleza, por sua vez, garante a materialidade das tendências de comportamento, que se concretizam através de objetos e produtos consumíveis (CASTRO, 2003).

De um ponto de vista discursivo, podemos dizer que o corpo não é uma entidade física dada, a priori, mas sim uma entidade constituída através da interação e do discurso. Nessa mesma linha, a corporeidade passa a ser vista como parte integrante e inseparável das práticas discursivas. Como construtos discursivos, questões relativas ao peso, tamanho e formato do corpo são tematizadas e tornadas relevantes através das interações discursivas (sejam elas interações face a face, interações mediadas, ou quase-interações mediadas (CHOULIARAKI; FAIRCLOUGH, 1999), e essas questões são frequentemente usadas como forma de responsabilizar os atores sociais por suas ações (HEPBURN; WIGGINS, 2005).

\section{METODOLOGIA}

Nesta seção, descrevemos os procedimentos utilizados na coleta, análise e interpretação dos dados da pesquisa, enfocando as três dimensões de significado apontadas em Halliday e Hasan (1989) - ideacional, interpessoal e textual - para a construção de significados nas práticas sociais desempenhadas no gênero capa de revista.

\subsection{SELEÇÃO DAS REVISTAS FEMININAS}

Foram selecionadas para a presente análise cinco revistas femininas brasileiras ( $B o a$ Forma, Corpo a Corpo, Dieta Já!, Shape e Women's Health) que abordam diretamente a temática do culto ao corpo e à beleza, apresentando técnicas disciplinares como o vestuário, as dietas alimentares, os exercícios físicos e as cirurgias plásticas cosméticas. Dois critérios foram considerados para a seleção das revistas: (1) ano de publicação (2010 e 2011) e (2) periodicidade de circulação (mensal). 
Em termos das mulheres que posam para as capas dessas cinco revistas, em quatro delas (Boa Forma, Corpo a Corpo, Dieta Já! e Shape) as modelos são olimpianas ${ }^{3}$ ou celebridades do momento - atrizes, cantoras, etc. -, enquanto que em uma dessas publicações (Women's Health), as modelos são desconhecidas do grande público, apesar de estarem alinhadas ao padrão corporal hegemônico magro, esbelto e jovem.

\subsection{COLETA E SELEÇÃO DAS CAPAS DAS REVISTAS}

O gênero capa de revista é predominantemente multimodal, com ênfase no texto não verbal (imagens, fontes, cores, tamanhos, etc.) e funciona como uma "propaganda" que antecipa o conteúdo de uma revista de modo a persuadir o leitor a consumi-la (MCLOUGHIN, 2000, p. 5). Frequentemente, uma capa de revista é composta pelo título, imagem principal e/ou secundárias e pequenos textos (coverlines) com informações curtas que acompanham ou se sobrepõem à imagem principal.

Primeiramente, buscamos exemplares de capas nos respectivos sites de cada revista. Constatamos que algumas das revistas selecionadas não disponibilizam as capas nos sites e partimos, então, para a busca e coleta das capas no banco de imagens do Google (Google Imagens). No total, foram baixadas e arquivadas 120 capas de revistas. Dentre as capas coletadas, selecionamos aleatoriamente, para a análise descrita a seguir, cinco capas (um exemplar de cada revista). As seguintes capas foram selecionadas para a análise:

\section{Figura 1 - Capas das revistas analisadas}
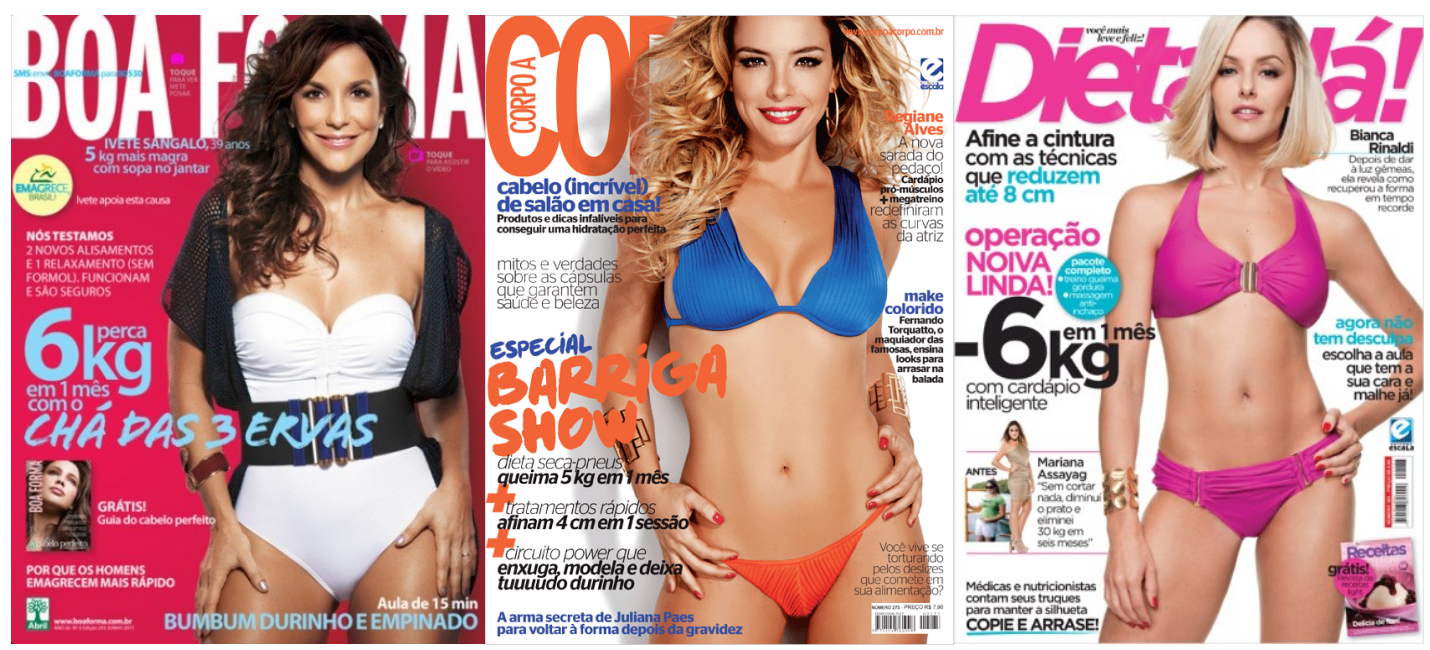

\footnotetext{
${ }^{3}$ Os "olimpianos" são definidos por Edgar Morin (1984) como aqueles seres transformados em "sobrehumanos" pela cultura de massa. São os astros e estrelas de cinema, os campeões esportivos, governantes, pintores e literatos célebres. A imprensa seria responsável por revesti-los de um caráter mitológico e, por outro lado, por buscar mergulhar em suas vidas privadas a fim de extrair delas a substância humana que permite a identificação.
} 


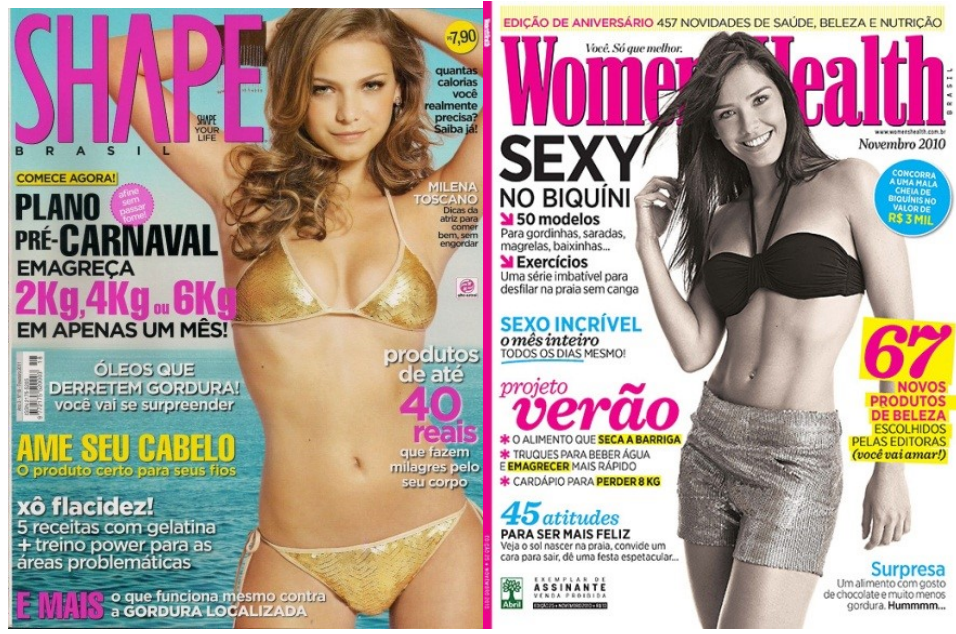

Fonte: Banco de imagens do Google (Google Imagens)

Na próxima seção, analisamos as cinco capas de revistas selecionadas (Figura 1) em termos do texto verbal e do texto não verbal (imagens). Com base nessa análise, buscamos compreender como a linguagem é constitutiva das práticas sociais ligadas ao culto ao corpo, e como a construção de uma identidade calcada em um projeto corporal se liga ao consumo de produtos e estilos de vida no discurso das revistas analisadas.

\section{A CONSTRUÇÃO DE SIGNIFICADO NAS CAPAS DE REVISTAS FEMININAS 6.1 ANÁLISE DO TEXTO NÃO VERBAL}

Nesta seção, exploramos os três tipos de significados descritos na Gramática Visual (KRESS; VAN LEEUWEN, 2006): significados representacionais (como as imagens representam os participantes, as ações desempenhadas por eles, e em que circunstâncias de tempo e espaço), significados interacionais (as relações estabelecidas entre a leitora e as participantes representadas) e significados composicionais (a organização, disposição dos elementos nas imagens).

\subsubsection{SIGNIFICADOS REPRESENTACIONAIS NAS CAPAS DE REVISTAS FEMININAS}

Nossa análise das imagens das capas das revistas femininas apontou para um padrão semiótico comum de construção de significados representacionais. Em termos da análise do texto não verbal, as cinco imagens analisadas (Figura 1) apresentam estruturas conceituais - as imagens representam um estado de ser no mundo - e as participantes (modelos), desse modo, não realizam nenhum tipo de ação, mas apenas posam para a fotógrafa, enfatizando seus atributos físicos ou corporais. ${ }^{4}$

\footnotetext{
${ }^{4}$ Como adotamos o feminino como genérico, utilizamos a expressão "a fotógrafa" aqui. Entretanto, compartilhamos da visão de John Berger (1972) de que o olhar que enquadra as fotografias da mídia de massas é um olhar masculino, independente do sexo/gênero do profissional envolvido.
} 
Especificamente, as imagens das capas são conceituais analíticas, nas quais os elementos estão relacionados por meio de uma estrutura parte-todo (KRESS; VAN LEEUWEN, 2006, p. 87) composta por dois tipos de participantes: o Portador (todo) e os Atributos Possessivos que o formam (partes). Nas capas analisadas, as modelos (todo) possuem uma série de atributos/partes (barriga "chapada", corpo "sarado", bumbum "perfeito", etc.) que as identificam com um modelo de corpo feminino (todo), e que são explicitamente nomeados nas coverlines (chamadas de capa) que acompanham as imagens.

Apesar desse padrão semiótico comum, constatamos que as modelos das capas analisadas apresentam diferenças em termos dos atributos que possuem (com exceção da barriga "chapada", um atributo aparentemente 'universal' e 'imprescindível' nessa representação de corpo belo feminino). Por exemplo, a modelo de capa da revista Corpo a Corpo (a atriz Regiane Alves) usa maquiagem pesada, batom e unhas vermelhas e cabelos volumosos, enquanto a modelo de capa da revista Women's Health usa maquiagem discreta, está mais vestida e usa o cabelo mais 'natural'. Os atributos que cada modelo de capa apresenta, portanto, constroem, na totalidade, um tipo de corpo e feminilidade vendido por cada revista para um determinado segmento do público consumidor. A mulher de capa da Corpo a Corpo, por exemplo, incorpora uma feminilidade do tipo sexy, glamorosa, ao passo que a modelo desconhecida da capa da Women's Health incorpora uma feminilidade do tipo the girl next door (uma garota jovem, simpática, bem-educada e bonita).

Nossa suposição é que a escolha de uma garota branca razoavelmente 'comum' como modelo de capa é resultante do contexto de produção da revista. A Women 's/Men's Health é uma franquia norte-americana voltada para um segmento consumidor específico nos EUA: homens e mulheres brancos, jovens, classe média/alta. Ao contrário da WH brasileira, a versão norte-americana traz jovens olimpianas conhecidas do público norteamericano (cf. pesquisa informal no banco de imagens do Google). Pensamos que um diferente formato de revista é adotado no Brasil porque a maior parcela consumidora da Women's Health é oriunda das classes média/alta ${ }^{5}$, em contraste com as leitoras das outras revistas. Essa parcela da população geralmente não consome a cultura popular da mídia brasileira, mas utiliza-se de outros meios de entretenimento (TV a cabo e tecnologias de transmissão de vídeo online, por exemplo). Desse modo, uma modelo desconhecida, branca e saudável na capa dessa revista torna-se um referencial 'conhecido' para garotas de classe média/alta, considerando-se que as celebridades da mídia norte-americana geralmente são desconhecidas do público brasileiro (com exceção das celebridades 'globais' como Beyoncé, Mariah Carey, Madonna, etc.).

Alguns traços comuns entre todas as modelos retratadas nas capas são sua afiliação étnica, de classe, de sexualidade e de faixa etária: a maioria esmagadora representa um modelo de beleza feminina branca, de classe média e jovem, ${ }^{6}$ corroborando nosso

\footnotetext{
${ }^{5}$ De acordo com dados sobre o perfil da leitora, cf. estudos realizados pela empresa Ipsos Marplan, referência nos estudos dos hábitos de mídia e consumo, as leitoras da Women's Health apresentam menor faixa etária (entre 20 e 34 anos) e pertencem em sua maioria à classe B (67\%).

${ }^{6} \mathrm{Há}$ pouquíssima diversidade quanto às etnias apresentadas no universo das 120 capas de revista coletadas. Desse total, apenas três capas retratam celebridades negras, no caso as atrizes brasileiras Sheron Menezes 
argumento de que as identidades acessíveis a cada consumidora em seu processo de individualização vão depender, principalmente, de sua classe social e seu poder de compra. $^{7}$

\subsubsection{SIGNIFICADOS INTERACIONAIS NAS CAPAS DAS REVISTAS FEMININAS}

Uma característica presente na capa das revistas analisadas é a ausência de cenário (background) nas fotos, comum nas imagens analíticas típicas do contexto da moda (KRESS; VAN LEEUWEN, 2006), por exemplo. Em termo dos significados interacionais, um maior ou menor detalhamento do cenário (contextualização) de uma imagem é geralmente visto como um marcador de modalidade, indicando à leitora o grau de verdade ou credibilidade de uma construção visual (KRESS; VAN LEEUWEN, 2006, p. 155). Por exemplo, as capas de quatro das cinco revistas analisadas (Women's Health, Corpo a Corpo, Dieta Já! e Boa Forma) apresentam um cenário plano não-modulado no qual as participantes são representadas em um vácuo e não estão conectadas a nenhuma circunstância espacial ou temporal. Nessas capas, a ausência de cenário indica para a leitora um baixo grau de modalidade, diminuindo o grau de realismo da imagem.

De modo geral, a ausência de cenário nas capas é adequada para o propósito comunicativo das estruturas conceituais analíticas, nas quais a interação é mais importante do que a representação (MOTTA-ROTH; NASCIMENTO, 2009, p. 339). Nas capas das revistas femininas, o principal objetivo é focar a atenção da leitora nos atributos físicos das modelos, que compõem o padrão estético corporal vendido pela revista. Um cenário mais detalhado poderia, portanto, desviar a atenção da leitora para detalhes secundários, comprometendo a eficácia retórica da composição visual (KRESS; VAN LEEUWEN, 1996, p. 90-93).

Por outro lado, a capa da Shape (Figura 2) é mais contextualizada em comparação com as capas das outras revistas, apresentando mar e céu azuis, o que parece indicar um maior grau de modalidade.

Entretanto, a presença de cenário em todas as capas dessa revista não nos parece apenas um marcador de maior modalidade (conforme apontado na próxima seção), mas um dos elementos que constituem um Processo Simbólico Atributivo, ou seja, "o que um participante é ou significa" em termos dos atributos simbólicos que ele (Portador) carrega (KRESS; VAN LEEUWEN, 2006, p. 105). Kress e van Leeuwen apontam que os processos simbólicos são "objetos" geralmente caracterizados por um dos seguintes

\footnotetext{
e Juliana Alves e a cantora americana Beyoncé. Quanto à variável 'idade', o espectro também se mostrou pequeno no corpus coletado. Das 120 modelos clicadas para as capas coletadas, apenas quatro tinham idades acima dos 40 anos (Christiane Torloni, Maitê Proença, Claudia Ohana e Luiza Brunet).

7 A pós-modernidade trouxe uma redistribuição das liberdades individuais, agora mais fortemente polarizadas entre as elites e as classes trabalhadoras (BAUMAN, 2001). Se aplicarmos essa premissa aos consumidores das classes trabalhadoras e baixas, podemos ver que a polarização das liberdades individuais e da segurança significa, para eles, impotência e insegurança crescentes, impedindo a concretização da promessa mercadológica da individualização: a total liberdade de autoconstituição e autoafirmação através do consumo.
} 
traços: saliência (foreground), presença de um gesto que aponta o atributo para a leitora, deslocamento em relação ao todo e associação convencional com valores simbólicos.

Figura 2 - Capa da revista Shape (2010)

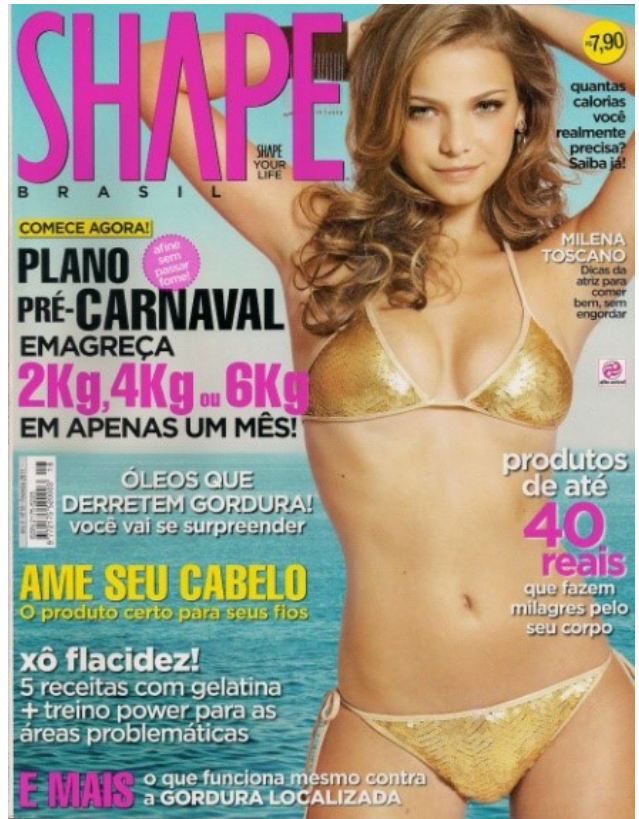

Fonte: banco de imagens do Google (Google Imagens)

No caso da revista Shape (Figura 2), os atributos apresentados pela modelo (pele, cabelos e biquíni dourados), em conjunto como o cenário (mar e céu azuis), aludem a significados simbólicos típicos da cultura de praia e de verão, como sol, calor e sensualidade. Esses significados, portanto, são constitutivos da identidade da participante representada. A Shape também é uma franquia norte-americana e a escolha dos significados simbólicos na capa da revista reflete o modo como a cultura brasileira é vendida internacionalmente e a importância do corpo como capital na cultura brasileira (GOLDENBERG, 2011), especialmente na Zona Sul do Rio de Janeiro. Desse modo, a Shape, como a Women's Health, também parece ser destinada para as classes médias.

Além da presença de cenário como uma característica particular da capa da revista Shape, também identificamos variações no uso de cor nas imagens de capa da revista Women's Health. Nas imagens de capa dessa revista (Figura 3), publicadas no ano de 2010, as modelos são retratadas em cores monocromáticas (preto e branco e tonalidades de sépia), em contraste com as imagens coloridas das capas das outras revistas analisadas.

De acordo com Kress e van Leeuwen (2006, p. 166), o grau de saturação da cor é também um marcador de modalidade, indicando o grau de "realismo" da imagem. No caso das imagens naturalistas ou fotorealistas, o uso moderado de cores em uma escala de saturação indica um alto grau de verossimilhança entre imagem e realidade, ao passo que a ausência total de cores (preto e branco) nessa escala diminuiria significativamente o grau de credibilidade junto à leitora (p. 165). 


\section{Figura 3 - Capa da revista Women's Health}

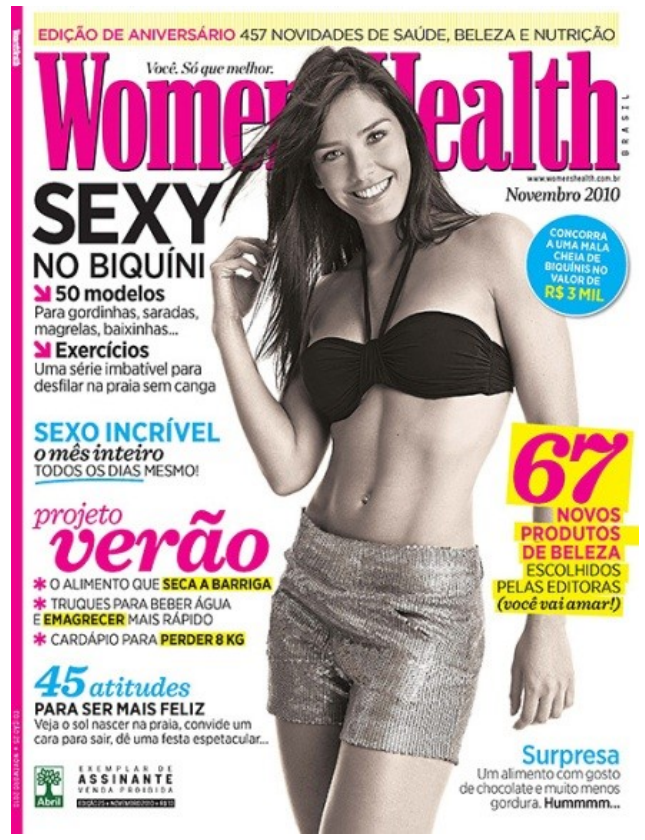

Fonte: banco de imagens do Google (Google Imagens)

Com relação à distância entre a leitora e as participantes (modelos) representadas, as imagens apresentam enquadramento mediano, indicando que a distância entre a leitora e as modelos é social. As modelos, desse modo, estão a uma distância que possibilita a interação. Por outro lado, verticalmente o ângulo que predomina é alto, uma característica que parece indicar a superioridade das modelos, representantes de sucesso no modelamento do corpo magro e saudável, e no estilo de vida bem-sucedido vendido pelas revistas.

A possibilidade de interação entre as modelos e as leitoras se faz visível por meio do contato visual. Em todas as capas analisadas, as modelos estão olhando diretamente para a leitora, exercendo uma forma de demanda (KRESS; VAN LEEUWEN, 2006), chamando a atenção para a necessidade de a leitora 'adquirir' um corpo 'malhado', dentro dos padrões de beleza vendidos pelas revistas.

Ao mesmo tempo, todas as modelos de capa são clicadas em um ângulo frontal, indicando o envolvimento subjetivo da leitora com as participantes representadas. As modelos não são observadas de modo objetivo (ângulo oblíquo), mas participam do mundo da leitora, interpelando-a da seguinte forma: "O que você vê aqui é possível de ser alcançado! Só depende de você".

O conjunto de escolhas para a construção de significados interacionais nas capas de revistas analisadas sugere, portanto, que as imagens das modelos das capas não oferecem uma representação verídica ou realista de uma pessoa ou acontecimento, mas visam ao estabelecimento de contato e interação com a leitora. Essa possibilidade de interação é garantida pela proximidade entre as duas, pelo ângulo frontal que estabelece uma perspectiva subjetiva e pelo olhar da modelo que interpela a leitora. 


\subsubsection{SIGNIFICADOS COMPOSICIONAIS NAS CAPAS DE REVISTAS FEMININAS}

Nas capas das revistas femininas analisadas, identificamos um padrão de organização centro-margem no qual a modelo ocupa a posição central e está cercada por chamadas verbais (coverlines) (KRESS; VAN LEEUWEN, 2006, p. 194). A modelo na capa é, portanto, o núcleo da informação e os outros elementos composicionais dependem dela.

A centralidade da modelo de capa é apontada também pela saliência ${ }^{8}$ que ela apresenta em relação aos outros elementos da capa. Nas revistas analisadas a imagem da modelo é o elemento que possui o maior tamanho na estrutura composicional e geralmente está sobreposto (foregrounded) ao título da revista. Com menos frequência (somente na revista Women's Health), as imagens das modelos estão em preto e branco, para destacá-las mais ainda do todo, como já mencionado na seção anterior.

Nas revistas analisadas, não há quadros dividindo os elementos da imagem. A imagem, desse modo, apresenta uma conexão máxima entre a modelo e os outros elementos que a circundam (título e coverlines). Além disso, as roupas que as modelos vestem costumam ter a mesma cor ou tons de cor parecidos com o do título da revista e de algumas chamadas selecionadas, de forma que as cores estabelecem relações semânticas entre os enunciados e as imagens.

\section{Figura 4 - Capa da revista Corpo a Corpo}

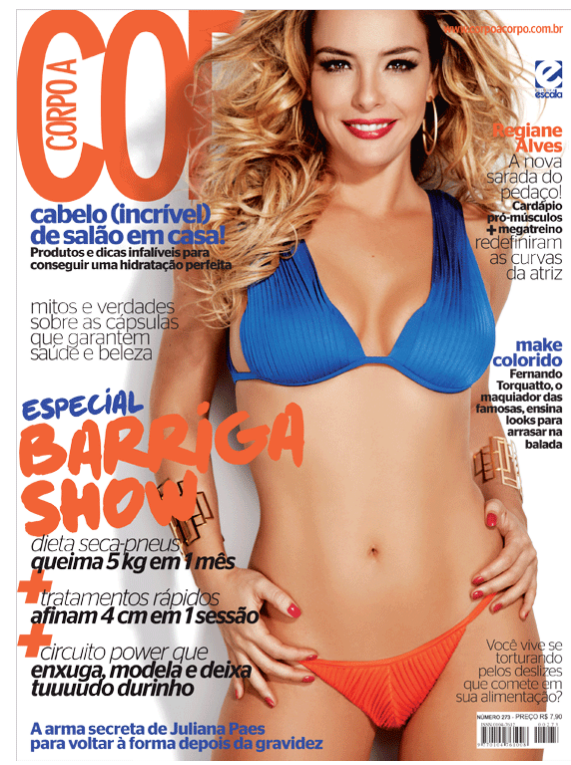

Fonte: banco de imagens do Google (Google Imagens)

\footnotetext{
${ }^{8}$ De acordo com a gramática visual de Kress e van Leeuwen (2006, p. 177), a saliência é grau de atração que os diferentes elementos de uma composição visual exercem sobre as leitoras, a qual varia de acordo com indicadores como tamanho, posição nos planos da figura (primeiro plano ou plano de fundo), saturação de cor e nitidez.
} 
Por exemplo, na capa da revista Corpo a Corpo (Figura 4), a atriz Regiane Alves veste um biquíni em duas cores. A parte de cima do biquíni (busto) é azul e a parte de baixo é laranja. As cores dessas peças de roupa da modelo são as mesmas utilizadas em algumas chamadas verbais e título da capa da revista. O título "Corpo a Corpo", "Barriga Show", os sinais de mais e o nome da atriz apresentam a mesma cor laranja, estabelecendo uma relação semântica de posse/atributo: a atriz Regiane Alves tem um corpo sarado, a barriga dela é "show". Por outro lado, a chamada "cabelo (incrível) de salão em casa!", "make colorido" e "A arma secreta de Juliana Paes para voltar à forma depois da gravidez" apresentam a mesma cor (azul) da parte de baixo do biquíni da modelo. Novamente, uma relação semântica de posse/atributo é estabelecida: Regiane Alves tem um "cabelo (incrível)", maquiagem ("make") colorida e, como a atriz Juliana Paes, ela tem uma "arma secreta", "especial", para manter a forma. A modelo de capa, portanto, personifica todos aqueles significados ou atributos expressos na linguagem verbal (magra, jovem, etc.) e é o elemento central, de maior destaque na composição visual, se constituindo na "expressão visual do divino e de algum outro poder superior" (ARNHEIM, 1982, p. 72 apud KRESS; VAN LEEUWEN, 2006)

A saliência e a centralidade da imagem da modelo em máxima conexão com as coverlines também pode ser interpretada como uma forma de garantir a interação com diversas leitoras que utilizam diferentes 'caminhos' na leitura dos textos. Para Kress e van Leeuwen (2006, p. 204-205), o caminho de leitura mais plausível no caso de textos que combinam semioses verbais e visuais é aquele no qual as leitoras primeiramente dão uma olhada nas fotos e, então, iniciam a leitura da esquerda para a direita, da chamada para a foto, para depois, opcionalmente, voltarem a atenção para o corpo do texto verbal. Entretanto, os autores alertam que esse caminho de leitura não é exclusivo, considerando que a saliência em uma imagem é culturamente determinada, variando de um grupo social para outro.

\subsection{ANÁLISE DO TEXTO VERBAL DAS CAPAS DE REVISTAS FEMININAS}

Nesta segunda seção, analisamos o texto verbal (títulos e coverlines) das capas das revistas femininas em termos de duas dimensões de significado descritas na Gramática Sistêmico-Funcional: metafunção ideacional e metafunção interpessoal ${ }^{9}$.

\subsection{1 "SEXY NO BIQUÍNl": (RE)CONSTRUINDO O CORPO NAS CAPAS DE REVISTAS FEMININAS}

Em nossa análise, constatamos que o padrão semiótico de estruturas conceituais analíticas nas imagens das capas, discutido anteriormente, é reforçado ou elaborado pelos textos verbais (títulos e coverlines) que acompanham essas imagens.

\footnotetext{
${ }^{9}$ Não incluímos a análise da metafunção textual da linguagem porque as capas de revistas são tipicamente compostas apenas por grupos nominais longos (conforme apontamos a seguir), impossibilitando, assim, a análise da ordenação dos elementos nas orações (tema-rema).
} 
Os títulos das revistas se constituem em estratégias discursivas bastante eficazes para a ativação de certas redes de significado e associações na mente das leitoras (MCLOUGHIN, 2000, p. 6). Dentre as cinco capas analisadas, quatro delas recorrem a substantivos ou grupos nominais que ativam determinados campos semânticos e sintetizam uma ideia geral do conteúdo presente em cada uma das revistas.

Por exemplo, o título Shape (em português forma, molde) faz referência à imagem, aparência externa, contorno e/ou forma do corpo de uma pessoa. Do mesmo modo, o título Boa Forma também faz referência a significados semelhantes, mas é mais específico ao definir explicitamente a forma (do corpo) como "boa", dando a entender, por tabela, que há também a forma corporal 'ruim', 'má'. Por outro lado, o título Women's Health indica a condição de um organismo ou pessoa (mulher) em um determinado momento, livre de doenças, apresentando "bem-estar" mental e/ou físico. Entretanto, como mostraremos a seguir, essa condição de mulher "saudável" sugerida pelo título está associada a um modelo corporal específico que é revelado pelas chamadas (coverlines) presentes na capa da revista. Em contraste com os títulos das outras revistas, o título Dieta Já! é um imperativo que demanda uma ação da leitora: se submeter a um programa de regime alimentar com o objetivo de perder peso, reduzir medidas e "modelar" o corpo de acordo com um determinado padrão estético.

Prosseguindo com a análise dos significados construídos pelo texto verbal nas capas, percebemos que as chamadas de capa das revistas femininas analisadas geralmente: (1) "nomeiam" os atributos possuídos pelas modelos e/ou (2) avaliam os produtos e as técnicas corporais anunciados para a modelagem do corpo feminino, o que deixa claro o vínculo entre o discurso do culto ao corpo e o discurso do consumo. Essa nomeação é predominantemente realizada por grupos nominais longos, com núcleos modificados por qualificadores e orações encaixadas que funcionam como circunstâncias (de modo ou propósito). Segundo McLoughin (2000, p. 15), uma das razões para o uso de grupos nominais longos é a necessidade da redatora do texto "encapsular" um grande número de informações em um espaço reduzido de forma a antecipar o conteúdo da revista para a leitora, como podemos ver nos exemplos abaixo:

\section{WH\#1 - 45 atitudes para ser mais feliz ${ }^{10}$}

No exemplo WH\#1, há um grupo nominal composto pelo núcleo (45 atitudes) e uma circunstância de propósito que apresenta uma oração relacional encaixada ([você] ser mais feliz). Por meio dessa chamada, a revista aponta para a leitora (nesse ponto assemelhando-se ao discurso de autoajuda) quais as atitudes "adequadas" para que ela alcance um 'estado de felicidade' ("ser mais feliz"). A 'felicidade' é uma das promessas do modelo de feminilidade vendido pela revista Women's Health, plasmado na imagem da modelo sorridente.

\footnotetext{
${ }^{10}$ Utilizamos a seguinte notação para fazer referência aos exemplos retirados de cada capa de revista: abreviação do nome da revista (BF- Boa Forma, CC - Corpo a Corpo, DJ - Dieta Já!, SH - Shape e WH Women's Health) seguida do número do exemplo (\#1, \#2, \#3...). 
CC\#2 - Cabelo (incrível) de salão em casa! Produtos e dicas infalíveis para conseguir uma hidratação perfeita

O exemplo $\mathrm{CC} \# 2$ descreve um dos atributos desejáveis ("cabelo (incrível) de salão") para as mulheres que almejam alcançar o padrão de feminilidade incorporado pela atriz Regiane Alves, modelo da capa, que apresenta uma cabeleira supostamente "incrível". Em seguida, nesse mesmo exemplo, a chamada antecipa o conteúdo da revista, com a promessa de "produtos e dicas" (núcleo do grupo nominal) para que a leitora possa cuidar do cabelo em sua própria casa e "conseguir uma hidratação perfeita" (circunstância de propósito). Nessa chamada, é importante salientar a escolha de qualificadores ("incrivel", "infaliveis", "perfeita") alinhados a uma estética do 'fantástico', típica da linguagem jornalística.

Como já mencionamos anteriormente, o texto verbal das capas das revistas geralmente apresenta somente grupos nominais para a construção dos significados ideacionais. Entretanto, a revista Dieta Já! também apresenta orações inteiras, às vezes com estrutura complexa:

DJ\#5 - Depois de dar à luz gêmeas, Bianca Rinaldi revela como recuperou a forma em tempo recorde.

No Exemplo DJ\#5, há apenas uma oração principal composta pelos seguintes participantes: dizente (elíptico - [ela]), processo verbal ("revela"), receptor (elíptico [para você]), verbiagem ("como recuperou a forma física em tempo recorde") e circunstância de tempo-localização ("Depois de dar a luz gêmeas"). Nessa oração, é importante notar a presença do verbo "relata" para a representação de uma "atividade" de fala (HALLIDAY, 2004, p. 255) e de uma oração projetada na forma de verbiagem ("como [ela] recuperou a forma em tempo recorde"). No caso do Exemplo DJ\#5, o processo material transformativo ("recuperou") aparece na oração encaixada seguido de uma meta ("a forma"). Aqui vemos outro traço da construção contemporânea da identidade feminina de 'sucesso': 'sacrificar' seu corpo para a maternidade, uma 'causa nobre', é algo socialmente elogiável para as mulheres, contanto que após o 'sacrifício' elas voltem a se disciplinar e se realinhem rapidamente ao modelo de corpo magro e esbelto.

Apesar da presença de alguns processos verbais e mentais (tais como revelar, contar, ensinar), os processos materiais são aqueles utilizados com maior frequência nas chamadas das capas das revistas analisadas: 
Quadro 1 - Processos materiais nas capas das revistas femininas

\begin{tabular}{|c|c|c|c|c|}
\hline Revista & $\begin{array}{c}\text { Ator/ } \\
\text { Circunstância } \\
\text { (Modo)/ } \\
\text { Grupo nominal }\end{array}$ & $\begin{array}{l}\text { Processo } \\
\text { Material }\end{array}$ & $\begin{array}{c}\text { Meta/ } \\
\text { Circunstância } \\
\text { (Propósito) }\end{array}$ & $\begin{array}{l}\text { Circunstância } \\
\text { (Tempo) }\end{array}$ \\
\hline \multirow{2}{*}{ Dieta Já! } & $\begin{array}{c}5 \text { receitas com } \\
\text { gelatina }+ \text { treino } \\
\text { power }\end{array}$ & & $\begin{array}{l}\text { para as áreas } \\
\text { problemáticas }\end{array}$ & \\
\hline & Sem cortar nada & $\begin{array}{c}\text { diminuí [o prato } \\
\text { e] } \\
\text { eliminei }\end{array}$ & $30 \mathrm{~kg}$ & em seis meses \\
\hline \multirow{2}{*}{ Corpo a corpo } & Dieta seca-pneus & queima & $5 \mathrm{kgs}$ & em um mês \\
\hline & Tratamentos rápidos & afinam & $4 \mathrm{~cm}$ & em uma sessão \\
\hline \multirow{2}{*}{ Shape } & $\mathrm{O}$ produto certo & & para seus fios & \\
\hline & Óleos & (que) derretem & gordura & \\
\hline $\begin{array}{l}\text { Women's } \\
\text { Health }\end{array}$ & $\mathrm{O}$ alimento & (que) seca & a barriga & \\
\hline Boa Forma & $\begin{array}{l}\text { A arma secreta de } \\
\text { Juliana Paes }\end{array}$ & & para voltar à forma & depois da gravidez \\
\hline
\end{tabular}

No Quadro 1, as orações/grupos nominais apresentam processos materiais do tipo transformativo (queima, afinam, derretem, seca, diminui, eliminei) que representam as transformações corporais prometidas pelo uso de produtos (óleos, produto certo), alimentos/receitas/dietas (5 receitas com gelatina, o alimento, dieta seca-pneus) e técnicas/tratamentos corporais (treino power, tratamentos rápidos, a arma secreta de Juliana Paes) que funcionam como 'atores' não-humanos. Nas orações, o processo material é geralmente seguido de uma Meta ( $5 \mathrm{kgs}, 4 \mathrm{~cm}$, gordura, a barriga), ao passo que nos sintagmas nominais, há geralmente apenas um grupo nominal seguido de uma circunstância de propósito (para as áreas problemáticas, para voltar à forma). Além disso, algumas orações/sintagmas apresentam uma circunstância que aponta o tempo necessário para que a 'transformação' ocorra (em um mês, em uma sessão) ou que a situa em um período determinado de tempo (depois da gravidez).

As escolhas léxico-gramaticais nas capas das cinco revistas femininas analisadas indicam que a transformação, modificação ou adequação do corpo 'problemático' a um ideal de beleza "magra" hegemônica deva ser uma necessidade urgente na vida das mulheres brasileiras que aspiram ao sucesso, seja na vida pública ou na vida privada. Esse ideal de sucesso e felicidade é corporificado pela modelo da capa e, mais raramente, por outras leitoras que adquiriram uma silhueta enxuta, 'desejável' e supostamente saudável. No processo de transformação ou "docilização" do corpo, cria-se uma metáfora de guerra (“a arma secreta”, "os truques", “operação noiva linda!”, etc.) na qual a leitora utiliza soluções rápidas e instantâneas para resolver seus problemas corporais. Há, desse modo, a criação de um nexo causal quase mágico entre a aquisição de produtos 'milagrosos' e a obtenção de um corpo belo e livre de imperfeições, que supostamente garantiria a posse e manutenção de uma identidade feminina bem-sucedida. 
Nas coverlines das cinco capas de revistas femininas analisadas, as redatoras e as leitoras assumem funções discursivas bem definidas nas interações. Nessas interações, há geralmente a troca de bens e serviços (HALLIDAY, 2004 p. 107), nas quais as redatoras (por meio das coverlines) demandam das leitoras, por meio de orações no modo imperativo, ações no mundo (comandos) em termos de:

1. Uso de tratamentos e produtos estéticos para o corpo SH\#8 - Ame seu cabelo [use] o produto certo para seus fios CC\#9 - [Faça um] cabelo incrível de salão em casa!

2. Adoção de tipos distintos de exercícios físicos e regimes alimentares para o emagrecimento/modelamento do corpo

DJ\#10 - Agora não tem desculpa escolha a aula certa que tem a sua cara e malhe já!

WH\#11 - Exercícios [faça ou adote] uma série imbatível para desfilar na praia sem canga SH\#12- Comece agora! Plano pré-carnaval emagreça $2 \mathrm{~kg}, 4 \mathrm{~kg}$ ou $6 \mathrm{~kg}$ em um mês BF\#13 - Perca 6kg em um mês com o chá das 3 ervas

3. Atividades de lazer e relações íntimas WH\#14 - [Faça $]$ sexo incrível o mês inteiro todos os dias mesmo! WH\#15 - Veja o sol nascer na praia, convide um cara para sair, dê uma festa espetacular...

Nas chamadas das capas analisadas, identificamos também, com menor frequência, a troca de informações por meio de orações declarativas, nas quais um especialista em saúde ou beleza (médico, nutricionista, cabeleireiro, etc.) fornece 'dicas' e 'truques' para a leitora supostamente leiga. A troca de informações também está presente na revista Dieta Já!, porém nessa revista há uma tendência ao uso do discurso testemunhal, no qual uma leitora selecionada fornece informações, contando sua experiência pessoal de emagrecimento e servindo como um modelo a ser seguido pelas demais leitoras:

CC\#16 - Make colorido Fernando Torquatto, o maquiador das estrelas, ensina looks para arrasar na balada

DJ\#17 - Médicas e nutricionistas contam seus truques para manter a silhueta. Copie e arrase!

DJ\#18 - Mariana Assayeg "Sem cortar nada, diminuí o prato e eliminei $30 \mathrm{~kg}$ em seis meses"

Orações no modo interrogativo, sugerindo demanda de informações (perguntas), também estão presentes nas capas das revistas analisadas. Entretanto, as perguntas são retóricas, pois é no conteúdo da revista que a leitora encontra as respostas. Há, desse modo, a criação de um padrão textual problema-solução, no qual a revista feminina se torna um manual que oferece soluções para a leitora que enfrenta problemas relacionados à manutenção do corpo 'magro' e precisa aprender a 'controlar' a alimentação: 
CC\#19 - Você vive se torturando pelos deslizes que comete em sua alimentação?

SH\#20 - Quantas calorias você realmente precisa? Saiba mais!

\section{COMENTÁRIOS FINAIS}

O discurso do culto ao corpo, como forma disciplinar, é um importante recurso utilizado para docilizar nossos corpos e desviar nosso olhar das questões estruturais e sistêmicas que nos afligem na contemporaneidade (como a concentração cada vez maior de riquezas e a globalização da miséria, as desigualdades geradas e mantidas por hierarquias de classe, gênero e raça, o desemprego estrutural, a fragilização das relações trabalhistas, a competitividade, a falência do modelo de produção capitalista neoliberal, a destruição do meio ambiente natural, a baixa qualidade de vida nas grandes áreas urbanas). Nas capas das revistas femininas analisadas, esse discurso é materializado nas imagens das modelos e seus atributos físicos, que constroem um tipo de corpo e feminilidade vendido por cada revista para um determinado segmento do público consumidor. Nessas capas, o principal objetivo é focar a atenção da leitora nas características físicas das modelos como estratégia de venda dos produtos/serviços promovidos nos textos verbais, que prometem soluções muitas vezes imaginárias para reduzir a complexidade de nossas condições contemporâneas.

Nessa mesma linha, os textos verbais "nomeiam" os atributos das modelos e/ou avaliam os produtos e as técnicas corporais anunciados para a modelagem do corpo feminino, o que deixa claro o vínculo entre o discurso do culto ao corpo e o discurso do consumo. A adequação do corpo da leitora ao ideal construído e prometido pelas capas é representada como um imperativo inescapável para que a mulher brasileira alcance a tríade beleza-saúde-felicidade. Essa tríade é geralmente representada pela modelocelebridade da capa e, mais raramente, por uma leitora que também 'adquiriu' um corpo canônico de sucesso (branco, magro, curvilíneo, bem vestido). E esse processo de construção de um estilo de vida e uma identidade 'de sucesso', no marco de nossos tempos líquidos, móveis e fragmentados, deve ser rápido, daí a promessa midiática de que ele pode ser alcançado por meio das soluções quase mágicas ou instantâneas representadas pelos produtos e serviços promovidos.

Em resumo, o discurso das revistas femininas 'vende' todos os dias a promessa de felicidade, beleza, saúde e sucesso para aquelas mulheres que docilizarem seus corpos e mentes, embarcando nas práticas de consumo que compõem o culto ao corpo e a estetização geral da vida humana. Mulheres individuais são ensinadas, através dos modelos corporais, dos estilos de vida e das identidades femininas postos em circulação e legitimados diariamente nos discursos midiáticos, a buscarem soluções cosméticas e pessoais para pressões sistêmicas (por ex., o imperativo do corpo magro, a fobia ao sobrepeso e à gordura, o imperativo da juventude, o imperativo da felicidade constante e instantânea), e que recursos usar para construir identidades 'bem sucedidas' e felizes. Entretanto, o acesso a essas soluções e, consequentemente, aos estilos de vida disponíveis, depende da capacidade individual de consumo dessas mulheres, determinadas por suas posições em hierarquias de classe. 
BAUMAN, Z. A sociedade individualizada. Rio de Janeiro: Jorge Zahar, 2001.

BERGER, J. Ways of seeing. London: British Broadcasting Corporation and Penguin Books, 1972.

BOURDIEU, P. Distinction: A social critique of the judgment of taste. London: Routledge and Kegan Paul, 1984.

CASTRO, A. L. de. Culto ao corpo e sociedade: mídia, estilos de vida e cultura de consumo. São Paulo: Annablume, 2003.

CHOULIARAKI, L.; FAIRCLOUGH, N. Discourse in late modernity. Edinburgh: Edinburgh University Press, 1999.

FAIRCLOUGH, N. A análise crítica do discurso e a mercantilização do discurso público: as universidades. In: MAGALHÃES, C. (Org.) Reflexões sobre a análise crítica do discurso. Belo Horizonte: FALE-UFMG, 2001, p. 31-82.

FRIDMAN, L. C. Vertigens pós-modernas (Giddens, Touraine, Bauman). Lua Nova (Impresso), São Paulo, v. 47, p. 157-177, 1999.

GIDDENS, A. Modernity and self-identity. Cambridge: Polity, 1991.

GOLDENBERG, M. Corpo, envelhecimento e felicidade na cultura brasileira. Contemporânea, v.9, n.2, p. 75-85, 2011.

HALLIDAY, M.; HASAN, R. Language, context and text: Aspects of language in a social semiotic perspective. Oxford: Oxford University Press, 1989.

HALLIDAY, M.; MATTHIESSEN, C. M. I. M. An introduction to functional grammar. $3^{\text {rd }}$ Ed. London: Edward Arnold, 2004.

HEBERLE, V. Revistas para mulheres no século 21: ainda uma prática discursiva de consolidação ou de renovação de ideias? Linguagem em (Dis)curso, v.4, n.esp, p. 85-112, 2004.

HEPBURN, A.; WIGGINS, S. Size matters: Constructing accountable bodies in NSPCC helpline interaction. Discourse \& Society, v.16, n.5, p. 625-645, 2005.

JACKSON, P. Consumption and identity: The cultural politics of shopping. European Planning Studies, v.7, n.1, p. 25-39, 1999.

KRESS, G.; VAN LEEUWEN, T. Reading images: the grammar of visual design. London, Routledge, 1996/2006.

MCLOUGHIN, L. The language of magazines. London: Routledge, 2000.

MORIN, E. Cultura de massa no século XX: neurose. Rio de Janeiro: Forense Universitária, 1984.

MOTTA-ROTH, D.; NASCIMENTO, F. Transitivity in visual grammar: concepts and applications. Linguagem \& Ensino, v.12, n.2, p. 319-349, 2009.

Recebido em 15/07/16. Aprovado em: 30/12/16.

Title: Discourse, body cult and identity: Representations of the female body in Brazilian magazines

Authors: Débora de Carvalho Figueiredo; Fábio Santiago Nascimento; Maria Eduarda Rodrigues

\begin{abstract}
In this article, we investigate representations of the female body in Brazilian magazines for women in order to interpret and explain how new models of body and identity are connected to the phenomenon of commodification of discourse, and mainly to consumer culture. Five magazine covers were analyzed based on a systemic-functional perspective on language (HALLIDAY, 2004). Our analysis demonstrates that the visual focus on the cover girls' physical attributes, combined with the cover lines naming the attributes and/or evaluating advertised products, construct the link between the discourse of body cult and the discourse of commodification. The acquisition of products and services, therefore, becomes an inescapable prerogative in the lives of Brazilian women who individually seek the promise of health, beauty and success, according to their purchasing power.
\end{abstract}

Keywords: Critical discourse analysis. Women's magazine. Cult of the body. Commodification. Late modernity. 
Título: Discurso, culto al cuerpo e identidad: representaciones del cuerpo femenino en revistas brasileñas

Autores: Débora de Carvalho Figueiredo; Fábio Santiago Nascimento; Maria Eduarda Rodrigues

Resumen: En este artículo investigamos las representaciones del cuerpo femenino en revistas femeninas brasileñas, de manera a interpretar y explicar cómo los nuevos modelos de cuerpo e identidad están ligados al fenómeno de la co-modificación del discurso, principalmente con la cultura del consumo. Cinco portadas de revistas fueron analizadas bajo una perspectiva sistémica e funcional del lenguaje (HALLIDAY, 2004). Nuestro análisis demuestra que el enfoque visual en los atributos físicos de las modelos, en combinación con las llamadas de capa nombrando esos atributos y/o evaluando los productos anunciados construye el vínculo entre el discurso del culto al cuerpo y el discurso de la co-modificação. La adquisición de productos y servicios, de ese modo, se cambia en prerrogativa inescapable en la vida de mujeres brasileñas que buscan individualmente la promesa de salud, belleza y suceso, de acuerdo con sus capacidades de compra.

Palabras-clave: Análisis critica del discurso. Revista femenina. Culto al cuerpo. Comodificación. Modernidad tardía.

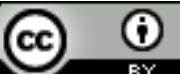

Este texto está licenciado com uma Licença Creative Commons Atribuição 4.0 Internacional. 